\title{
The matter of comparative studies of the national version of the poems: "Garip Ashiq Shakhsanem" (on The Examples Of Karakalpak, Uzbek And Turkmen Languages)
}

\author{
Allambergenov Kenesbay ${ }^{1}$ \\ ${ }^{I}$ Doctor of Philology, Professor, Uzbekistan
}

Haytbayeva Venera Mirzaliyevna

Independent researcher on the specialty Folklore, Department of Karakalpak Literature, Nukus State Pedagogical Institute named after Ajiniyaz

\begin{abstract}
This article is about the epic of a stranger and a lover in love and a comparative study of its national versions. Moreover, the matter of comparative studies of the national version of the poems. On this case "Garip Ashiq Shakhsanem" (on the examples of Karakalpak, Uzbek and Turkmen languages) has been analyzed and investigated both methodological and theoretically.
\end{abstract}

Keywords: Uzbek, oral, art, Alpomish, Surkhandarya, Termez, Qarluq, Kipchak and Oguz, baxshi.

\section{Introduction}

Structural-semiotic study of the plot system of epic works in Uzbek folklore, in particular, the study of the mythological and vital foundations of the epic series "Oshik", the artistic and aesthetic function of the text, the forms of artistic expression is one of the most pressing issues. is considered to reflect the spiritual image. During the years of independence, the principles of a new approach to oral art, which is an integral part of our national values, and their study in the interests of the restoration of our national, cultural, literary and historical values have been formed. After all, "the spirituality of any people or nation cannot be imagined without its history, unique customs and traditions, vital values" 1 . An objective reevaluation of folklore works, the international celebration of the millennium of the epic "Alpomish", the pride of the Uzbek people, the promotion of folklore performance and the establishment of titles of various levels, the publication of the 100th volume of Uzbek folk art monuments With the beginning of the 20th century, the opportunity to study the works of the epic type on the basis of different methods and theoretical views, the system of main motives, the stages of historical development and the art of their leading role in the plot expands.

\section{Main part}

It should be noted that the study of folk art on the basis of the latest theoretical concepts of modern world philology on the basis of the tasks set forth in the Strategy of Actions for the Further Development of the Republic of Uzbekistan should become a leading principle in our folklore today. This is because taking science and literature to a new level is one of the priorities in the development of the social sphere, which opens up even greater avenues for scientific research in this area. In addition, according to the recent resolution of the President of the Republic of Uzbekistan on November 1, 2018 "On the International Festival of the art of baxshi" in Surkhandarya region is scheduled to hold the International Festival of the art of baxshi every two years. It is no exaggeration to say that the first international baxshi festival will be held in Termez, Surkhandarya region, on April 10, according to the above decision. Epics that embody ancient epic traditions have the potential to have a strong artistic and aesthetic impact on the younger generation as they embody the mythological imaginations, beliefs, lifestyles and spirituality of our people. By researching and promoting them, we can learn a lot about the history of spirituality and culture of our nation. Therefore, an in-depth study of the specific artistic features of the epics will help to better understand the laws of artistic thinking of our people. The peoples of Central Asia, like the rest of the world, have their own ancient and rich culture and literary history. Our people are one of the oldest cradles of human culture. Some of the tribes in our area were nomads, while others were sedentary. Those who lived a nomadic life were engaged in animal husbandry and hunting, while those who lived in a sedentary way were engaged in farming and handicrafts. Over time, the people began to expand the use of artificial irrigation and construction. As a result of a long historical process, the tribes living in the Central Asian region have become confused. As a result, the fact that the Uzbek people are made up of three major ethnic groups has become a chrestmotic fact among scholars. In other words, the Uzbek people was formed on the basis of the unity of the Qarluq, Kipchak and Oguz tribes. Therefore, it would be a great mistake to ignore this issue in the study of folklore works that are directly related to the life, lifestyle and history of the people, especially in the study of their roots.Although the epic treasure of epics is considered to be a whole in folk art, we can clearly observe the unique spiritual phenomenon of each region. In our folklore, the epic poetry of Samarkand-Jizzakh, Surkhandarya-Kashkadarya, Tashkent, Fergana valley and Khorezm oasis are considered separately. This is not just a 
classification based on geographical-territorial boundaries. It is divided into groups, taking into account the ubiquitous epic traditions, the uniqueness of the baxshi in the performance, the epic repertoire and the poetic nature of the direct epics. Exactly, there is a method of performance in Khorezm epics, the compositional structure, melodies and a number of other aspects of epic works differ sharply from other dotonic centers of the republic. This is exactly the situation in Khorezmian epics, which is reflected in the following places: The singer-songwriter is accompanied by other musicians. The text of Khorezmian epics, especially their poetic part, is stable. S. Ruzimbaev writes about it: “..... the poems in the epics are rhythmically harmonized, polished, artistically perfect. For this reason, the poems in Khorezm epics are rhymed in a strict order and divided into verses 14. Another peculiarity is that most of the epic repertoire of Khorezm epics is of the romantic type. As for the specifics of the performance of the bakhshis, it is noted that today the bakhshis are popularizing their works in two ways. That is: a) orally through the repertoire of bakhshis and ensemble caliphs; b) by reading or listening to a book text through the repertoire of soloists and storytellers "15. Thus, the above-mentioned ideas show that Khorezm epic has a worthy place in the Uzbek epic art with its traditions, repertoire and other aspects. Thus, the scientific study and assessment of all aspects of epic creation in the region allowed to deepen the knowledge, scientific study and dissemination of the Uzbek epic to the general scientific community. In Uzbek folklore we can see that the division of epics into subcategories is based on the leading indicators of the interdependence of one or another pattern. That is, it is considered as a series of epics, which are based on the dynasty, life, specific epic space and time of any hero. For example, a series of epics related to the biography of the protagonist (small "Gorogly" and epics about Hasankhan, Avazkhan) or epics within the prose series (about Nurali and Ravshan). The tradition of categorizing epics into these categories stems directly from the analysis of works in the epic repertoire of bakhshis and their classification based on the above criteria.Based on these results, the grouping of epics into two groups is relatively common, and it is clear that most studies have focused on these groups.

\section{Conclusion}

In other words, the biographical series about the life of the hero and the genealogical epics about the life of his descendants have become the object of comprehensive research. In particular, the main criterion in the series of epics "in love" is that the protagonist is in love. S. Rozimbayev, devoting a section of the book "Khorezm epics" directly to "in love" and studying the specific features of the samples belonging to this category, pays special attention to this aspect of the issue. As the folklorist rightly points out, the protagonist of the series "Oshik" is a singer, a benefactor, a suffering lover. " All of our epic works, which are part of the dotons of the "oshiq" series, for example, in the epic "Oshiq Garib va Shohsanam", the famous bakhshi who sang with the Garib dutar was "ashug". Albandjon in the epic "Oshiq Alband" is also described as a mature disciple of Aydın Aydın. "Oshiq Najab", a sequel to this work, can also be seen as a lover. "Oshiq Mahmud" is one of them. In addition to being the leading feature of the protagonist in the Bakhshi (ashug) series of "love" epics, these aspects also serve as the main means for him to reach his mistress and overcome certain obstacles.

\section{References:}

\# Abdullayev V. "Oshiq Garib va Shohsanam" // History of Uzbek literature. Book

\# Tashkent, 1964. - Pages 43-44; 2. Child care. "Gharib va Shohsanam" // Literature and art of Uzbekistan. - 1938. - № 9 - pages 19-22;

\# Borges X.L. Serashnyy son // foreign literature. - Moscow, 1990.№ 3yu - S.179- 185.

* Grintser P.A. Epics of the ancient world // Typology and interrelationships of the literature of the ancient world. - Moscow: Nauka, 1971. S.183

\# Jkubaeva S. Variants of the epos "Ashyg Garib" in other nations // Researches on Azerbaijani oral folk literature Book 1 - Baku. 1961. B.215.

\# Eshankulov J. Dream and its study. // Uzbek language and literature. - 2001. №2. B.54-60.

\# Rozimbaev S. Peculiarities of epic clichés and traditional formulas in Khorezm epics // Uzbek language and literature. - 1990. - №2. B. 39. 